This is a peer-reviewed, accepted author manuscript of the following article: Costa, J. S., Rodríguez-Jiménez, S., Craig, G. A., Barth, B., Beavers, C. M., Teat, S. J., Gagnon, K. J., Barrios, L. A., Roubeau, O., \& Aromí, G. (2020). Selective signalling of alcohols by a molecular lattice and mechanism of single-crystal-to-single-crystal transformations. Inorganic Chemistry Frontiers, 7(17), 3165-3175.

https://doi.org/10.1039/D0QI00645A

\title{
ARTICLE
}

\section{Selective Signalling of Alcohols by Molecular Lattice and Mechanism of Single-Crystal-to-Single-Crystal Transformation.}

Received 00th January 20xx, Accepted 00th January 20xx

DOI: $10.1039 / \times 0 \times x 00000 x$

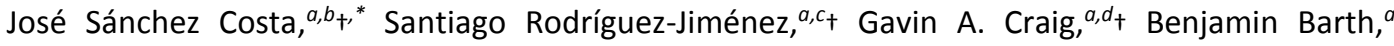 \\ Christine Beavers, ${ }^{e}$ Simon J. Teat, ${ }^{e}$ Kevin Gagnon, ${ }^{e}$ Leoní A. Barrios, $^{a, f}$ Olivier Roubeau $^{g}$ and Guillem \\ Aromíaf, $^{a, *}$
}

\section{Introduction}

Single-crystal-to-single-crystal (SCSC) transformations triggered by migration of small molecules through a lattice (absorption, desorption or exchange) are of increasing importance to a large variety of fields. These include gas absorption, separation or storage applications, ${ }^{1}$ heterogeneous catalysis, ${ }^{2,3}$ or chemica sensing and detection. ${ }^{4-6}$ Usually, such transformations are observed and exploited on materials that exhibit a 3D network of chemical bonds and pores, such as in metal-organic frameworks (MOFs) ${ }^{7-9}$ The first feature often prevents the lattice from collapsing as a result of structural or compositional changes. The second property furnishes easy channels for the transit of molecules. However, while equally interesting, it is more rare to witness SCSC compositional changes in molecular crystals, ${ }^{10-15}$ since they lack these two characteristics; the lattice components are connected by weaker intermolecular interactions and they are arranged under more degrees of

\footnotetext{
a. Departament de Química Inorgànica i Orgànica, Universitat de Barcelona Diagonal 645, 08028 Barcelona, Spain.E-mail: guillem.aromi@qi.ub.es. b.IMDEA Nanociencia, C/ Faraday 9, Ciudad Universitaria de Cantoblanco, 28049, Madrid, Spain.E-mail: jose.sanchezcosta@imdea.org

Department of Chemistry, University of Cambridge, Lensfield Road, Cambridge, CB2 1EW, UK

d. Department of Pure and Applied Chemistry, University of Strathclyde, Glasgow, UK

e. Advanced Light Source, Berkeley Laboratory, Cyclotron Road, Berkeley, CA 94720 (USA)

f. Institute of Nanoscience and Nanotechnology of the University of Barcelona (IN2UB), Barcelona, Spain

g. Instituto de Ciencia de Materiales de Aragón (ICMA), CSIC and Universidad de Zaragoza, Plaza San Francisco s/n, 50009, Zaragoza, Spain

† Present address.

Electronic Supplementary Information (ESI) available: [crystallographic tables and graphics, additional magnetic data, TGA details]. See DOI: 10.1039/x0xx00000x
}

freedom so as to minimise the empty space, thus not presenting empty pathways for the free circulation of species. Given the potential applications of these solid-state transformations in areas such as pharmaceutical research ${ }^{16,17}$-for example, as indirect methods to obtain polymorphs of crystalline molecular materials ${ }^{18-21}$ - it is an important challenge to understand and control their mechanism. Non(or nano)-porous molecular crystals capable of selectively absorbing small species may also be studied as solid-state chemical sensors, potentially at the micro- or nanoscale. ${ }^{22-28}$ This requires a mechanism to signal the detection upon incorporation of the analyte by the lattice, such as a change to the optical or magnetic properties. ${ }^{25}$, 29-33 The well-known phenomenon of spin crossover ( $\mathrm{SCO}$ ) would be ideal to implement this function. ${ }^{34-37}$ It involves a reversible transition by certain $d$-block metal ions between two accessible electronic (and spin) states triggered by an external stimulus such as temperature or pressure changes. Interestingly, a similar result may be induced by the inclusion/extrusion of analytes into/from the crystal lattice of the material, often near room temperature. Fe(II) within an octahedral coordination geometry is the most studied and exploited metal for its SCO properties because of the drastically different properties between its high-spin (HS, $S=2$ ) and a low-spin (LS, $S=0$ ie diamagnetic) states. ${ }^{38-41}$ The transition also causes a variation of $\approx 10 \%$ of the metal-to-ligand bond distances. ${ }^{42}$ Many molecular SCO materials made of discrete $\mathrm{Fe}(\mathrm{II})$ complexes have been reported to undergo absorption, desorption or substitution of lattice molecules coupled to a systematic change to their magnetic behaviour, most often in form of spin switching. ${ }^{18,22 \text {, }}$ 43-60 When these processes occur in a SCSC manner, the structural details associated with the transformation may be examined through single crystal X-ray diffraction (SCXRD). This 
technique provides a privileged window on the molecular structure of the material before and after the migration of lattice molecules, allowing the associated changes to the properties to be rationalised and to hypothesise about the mechanism of the transition. ${ }^{61}$ For this purpose, it would be of great value to gather structural information on a SCSC transformation at intermediate stages, while it is taking place. Such studies, however, are extremely scarce. ${ }^{62,63}$

Tris-imine complexes of $\mathrm{Fe}(\mathrm{II})$ are very widespread as SCO molecular materials. ${ }^{64-66}$ Most of them exhibit a dense network of intermolecular interactions that has been termed terpyridine embrace. ${ }^{67-69}$ This pattern seems flexible enough to facilitate the diffusion of small molecules through the lattice, while maintaining the integrity of the crystallographic order and single crystallinity. We and others have demonstrated that some members of this family of complexes are prone to undergo SCSC transformations following the transport of molecules through the lattice with well-defined stoichiometry. ${ }^{18,50,70,71}$ In particular, the heteroleptic complex $\left[\mathrm{Fe}(\mathrm{bpp})\left(\mathrm{H}_{2} \mathrm{~L}\right)\right]\left(\mathrm{ClO}_{4}\right)_{2} \cdot 1.5 \mathrm{C}_{3} \mathrm{H}_{6} \mathrm{O} \quad(\mathbf{1} \cdot \mathrm{Ac} ; \mathrm{bpp}, 2,6$-bis-(pyrazol-3yl)-pyridine; $\mathrm{H}_{2} \mathrm{~L}, 2,6$-bis-(5-(2-metoxyphen-1-yl)-pyrazol-3-yl)pyridine; Fig. 1 and 2) was found to convert into $\left[\mathrm{Fe}(\mathrm{bpp})\left(\mathrm{H}_{2} \mathrm{~L}\right)\right]\left(\mathrm{ClO}_{4}\right)_{2} \cdot \mathrm{C}_{3} \mathrm{H}_{6} \mathrm{O}(\mathbf{2} \cdot \mathrm{Ac})$ upon heating, wherein the remaining acetone molecules could be replaced by $\mathrm{MeOH}$ and $\mathrm{H}_{2} \mathrm{O}$, all this during the course of SCSC transformations. ${ }^{46}$ Remarkably, the 1·Ac $\rightarrow \mathbf{2} \cdot$ Ac transformation was analysed using SCXRD at various intermediate stages, unveiling the formation of a metastable ordered phase that could be characterised. ${ }^{72}$

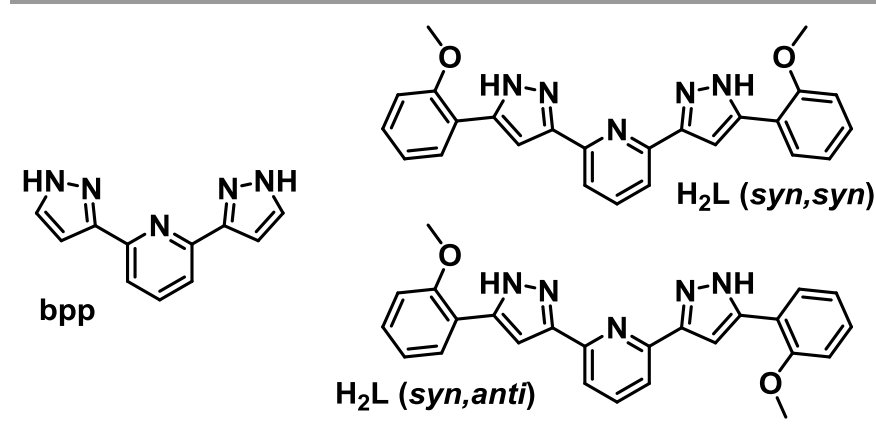

Figure 1. Representation of ligands bpp and $\mathrm{H}_{2} \mathrm{~L}$, emphasising two conformations of the latter, depending on the orientation of the distal methoxy groups with respect to the central pocket.

We report here that 2. Ac can absorb the larger alcohols EtOH and ${ }^{n} \mathrm{PrOH}$ at room temperature in exchange for acetone, while selectively, ${ }^{i} \mathrm{PrOH}$ is unable to enter the structure. In all cases, the structure of the resulting materials is accessible via SCXRD. The nature of the alcohol sensed can be distinguished by the magnetic properties of the detector material. All the resulting alcoholates can be depleted of their respective alcohol molecules upon gentle annealing. The SCSC desorption of $\mathrm{PrOH}$ has been studied by SCXRD determinations at various intermediate stages, unveiling a solid-state mechanism that differs from that previously described for the extrusion of acetone from 1.Ac. ${ }^{72}$ This study represents one of the first providing details of a solid-state transformation of a molecular material at intermediate stages, from SCXRD analysis.

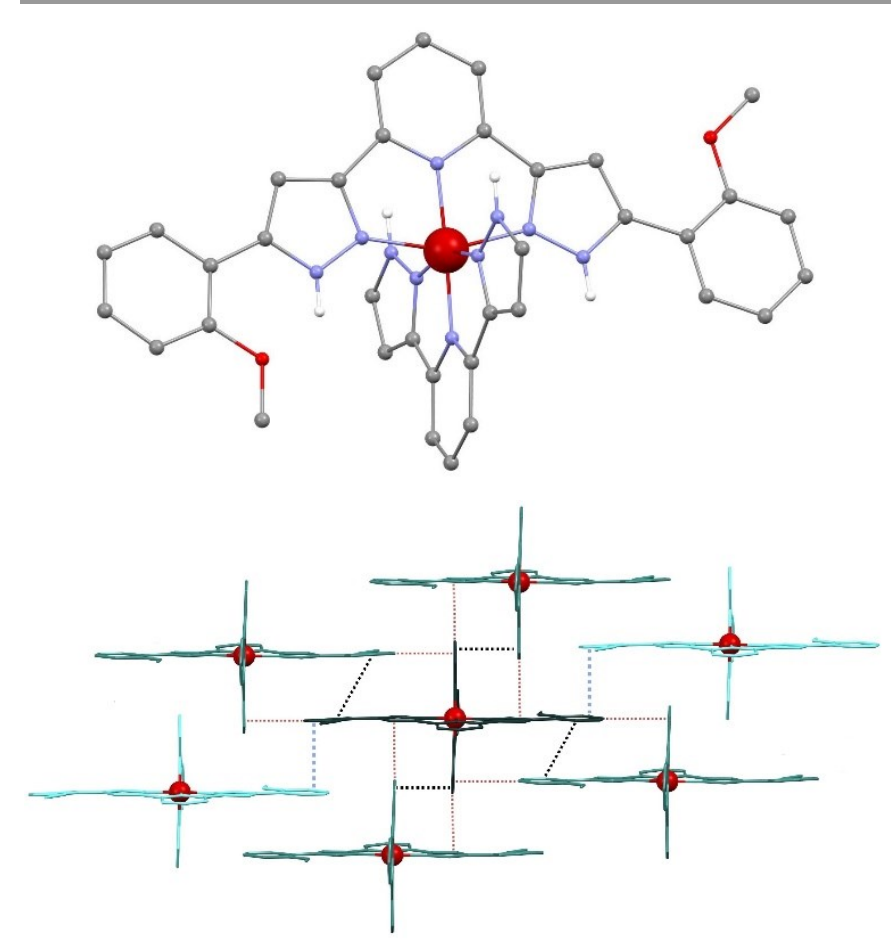

Figure 2. (top) Representation of the complex cation $\left[\mathrm{Fe}(\mathrm{bpp})\left(\mathrm{H}_{2} \mathrm{~L}\right)\right]^{2+}$, common to compounds discussed in this paper. Colour code: Fe, large red ball; $\mathrm{C}$, grey; N, blue; $\mathrm{H}$, white. Only hydrogen atoms bound to nitrogen atoms are shown. (bottom) Representation of the intermolecular interactions formed by the complexes with their four first neighbours (medium dark colour) and their two second neighbours (lightest colour), shown as dashed lines. The interactions with the first neighbours are $\pi \cdots \pi$ (black) and $\mathrm{C}-\mathrm{H} \cdots \pi$ (red) whereas those with second neighbours are only $\pi \cdots \pi$ (light blue).

\section{Results and discussion}

SCSC Transformation of $\left[\mathrm{Fe}(\mathrm{bpp})\left(\mathrm{H}_{2} \mathrm{~L}\right)\right]\left(\mathrm{ClO}_{4}\right)_{2} \cdot \mathrm{C}_{3} \mathrm{H}_{6} \mathrm{O}$ (2.AC) into $\left[\mathrm{Fe}(\mathrm{bpp})\left(\mathrm{H}_{2} \mathrm{~L}\right)\right]\left(\mathrm{ClO}_{4}\right)_{2} \cdot 1.25 \mathrm{MeOH} \cdot 0.5 \mathrm{H}_{2} \mathrm{O}$ $\left[\mathrm{Fe}(\mathrm{bpp})\left(\mathrm{H}_{2} \mathrm{~L}\right)\right]\left(\mathrm{ClO}_{4}\right)_{2} \cdot 1.5 \mathrm{EtOH} \cdot 0.5 \mathrm{H}_{2} \mathrm{O}$

(3.MeOH), $\left[\mathrm{Fe}(\mathrm{bpp})\left(\mathrm{H}_{2} \mathrm{~L}\right)\right]\left(\mathrm{ClO}_{4}\right)_{2} \cdot \mathrm{PrOH}$ (3.PrOH).

(3-EtOH) and

Compounds 3. $\mathrm{MeOH}, 3 \cdot \mathrm{EtOH}$ and 3.PrOH were obtained as single crystals through the exposure of $2 \cdot A$ to air saturated with vapour of methanol, ethanol or propanol, respectively. The structure of 2.Ac has been previously described. ${ }^{46,} 72$ It comprises a heteroleptic complex $\left[\mathrm{Fe}(\mathrm{bpp})\left(\mathrm{H}_{2} \mathrm{~L}\right)\right]^{2+}$ (Fig. 2), forming $\mathrm{H}$-bonds to two $\mathrm{ClO}_{4}^{-}$anions and to one molecule of acetone (Fig. S1), with the ligand $\mathrm{H}_{2} \mathrm{~L}$ lying in the "syn, anti" conformation (Fig. 1). The complexes exhibit an extended version of the terpyridine embrace pattern (Fig. 2, S2 and S3, Table S3). ${ }^{67}$ During each of the three processes of solvent exchange, the acetone contained in $\mathbf{2}$.Ac migrates through the non-porous molecular crystal of the compound to the exterior, while a fixed amount of molecules of the corresponding alcohol enter the lattice (together with 0.5 equivalents of water in the case of 3. $\mathrm{MeOH}$ and 3.EtOH). For all these transformations a drastic colour change takes place, from orange/yellow to very dark red (Fig. 3), which can serve as a mechanism for detecting the absorption of any of the three alcohols from the atmosphere around crystals of $\mathbf{2}$.Ac (see below). When crystals of 2.Ac where exposed to vapours of isopropanol, the alcohol did not enter the lattice, and the structure of the initial system 
2.Ac was retained. This observation is interesting, considering that 1-propanol and acetone enter the lattice. The contrast between the linear chain of ${ }^{n} \mathrm{PrOH}$ compared to the trigonal pyramidal geometry of ${ }^{i} \mathrm{PrOH}$ is certainly determinant. The mobility of acetone compared to isopropanol must be explained by the planarity and lower volume of the former. Perhaps the absence of hydrogen atoms on the oxygen atom of acetone facilitates its interaction as acceptor of the $\mathrm{N}-\mathrm{H}$ group, compared with 2-propanol. A marked selectivity with respect to two isomers is not easy to achieve and very few molecular materials have been reported to show this capacity. ${ }^{73}$ Here, in addition, we report a mechanism for signalling the detection (see below and Fig. 3).

The structure of 3. $\mathrm{MeOH}$ has already been described (Fig. S4). ${ }^{46}$ The asymmetric unit of its triclinic $\mathbf{P} \overline{\mathbf{1}}$ unit cell has the same composition as the formula. The replacement of one equivalent of acetone by 1.25 equivalents of $\mathrm{MeOH}$ and 0.5 equivalents of $\mathrm{H}_{2} \mathrm{O}$ causes a slight increase of the distance separating the sheets of complexes up to $10.341 \AA$ (Fig. S5), while the position and conformation of the complex cations as well as $2 \mathrm{D}$ pattern of intermolecular interactions are conserved (Fig. S6, Table S4).

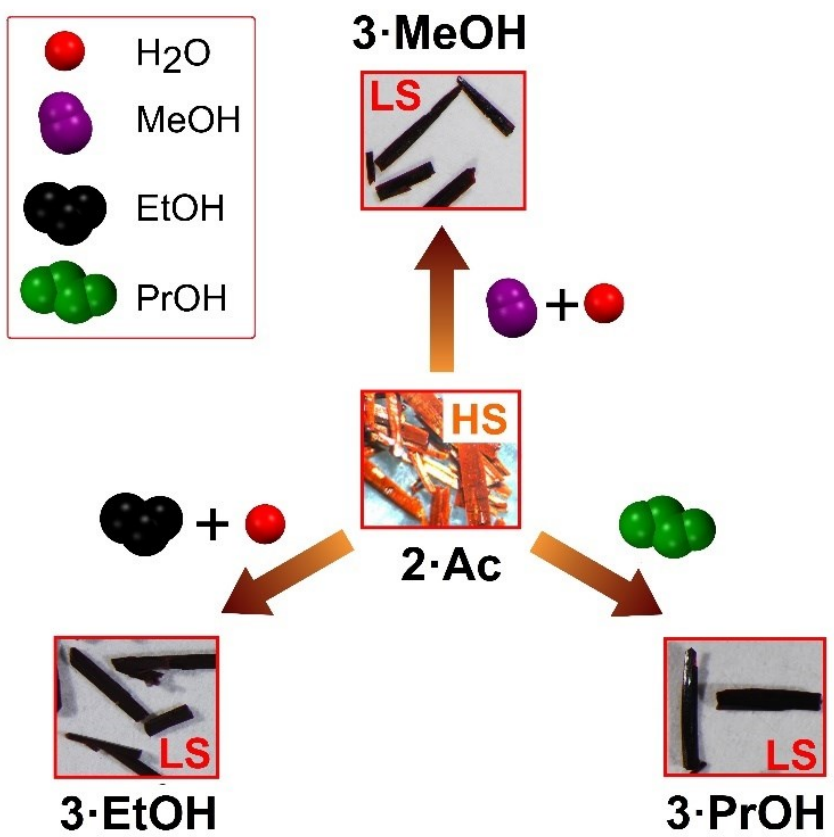

Figure 3. Photos of single crystals of compound 2. Ac prior to exposure to alcohol $(\mathrm{MeOH}$ $\mathrm{EtOH}$ or ${ }^{n} \mathrm{PrOH}$ ) vapours, and after absorption of alcohol molecules of these vapours, which yielded the compounds $3 \cdot \mathrm{MeOH}, 3 \cdot \mathrm{EtOH}$ and $\mathbf{3} \cdot \mathrm{PrOH}$.

Compound 3.EtOH is obtained by replacement of one equivalent of acetone from 2. Ac by 1.5 equivalents of $\mathrm{EtOH}$ and 0.5 of water, following a SCSC transformation. The resulting single crystals exhibit a structure in the triclinic $P \overline{\mathbf{1}}$ space group with its asymmetric unit coinciding with the formula given to this compound (Table S1). The latter contains the $\left[\mathrm{Fe}(\mathrm{bpp})\left(\mathrm{H}_{2} \mathrm{~L}\right)\right]^{2+}$ complex in the same conformation as $3 \cdot \mathrm{MeOH}$. The $\mathrm{ClO}_{4}{ }^{-}$anions and one molecule of ethanol establish $\mathrm{H}$-bonds with the $\mathrm{N}-\mathrm{H}$ groups of the complex cation (Fig. S7, Table S2) with the water accepting the $\mathrm{EtOH}$ proton as part of another $\mathrm{H}$ - bridge, also in perfect analogy with the structure of $3 \cdot \mathrm{MeOH}$. There is also a weakly bound molecule of $\mathrm{EtOH}$ with $50 \%$ occupancy located in between the sheets of complexes. The Fe$\mathrm{N}$ distances (average of 1.94(3) $\AA$ at $250 \mathrm{~K}$ ) denote that the process $\mathbf{2} \cdot \mathrm{Ac} \rightarrow \mathbf{3} \cdot \mathrm{EtOH}$ takes place together with a switch from the HS to LS state, while the resulting lattice of [Fe] complexes features the same terpy embrace pattern as all compounds described above (Fig. 2 and S8, Table S5). The separation between sheets of complexes within $3 \cdot \mathrm{EtOH}(10.356 \AA$ ) is very similar to that observed for $\mathbf{3} \cdot \mathrm{MeOH}$.

Exposure of yellow crystals of 2.Ac to vapours of $\mathrm{PrOH}$ at room temperature produces very dark red crystals of 3.PrOH. Despite being of very bad quality, these crystals are amenable to SCXRD determinations, which confirmed the identity of the compound. On the other hand, good quality single crystals of 3.PrOH were produced using a modified solid-state reaction (see $\mathrm{SI}$ ), which produced much better diffraction data. The structure of 3.PrOH belongs to the triclinic $P \overline{\mathbf{1}}$ space group with an asymmetric unit that contains the $\left[\mathrm{Fe}(\mathrm{bpp})\left(\mathrm{H}_{2} \mathrm{~L}\right)\right]^{2+}$ complex, hydrogen-bonded via $\mathrm{N}-\mathrm{H}$ groups to two $\mathrm{ClO}_{4}^{-}$counter-anions and one sole ordered molecule of PrOH (Fig. 4).

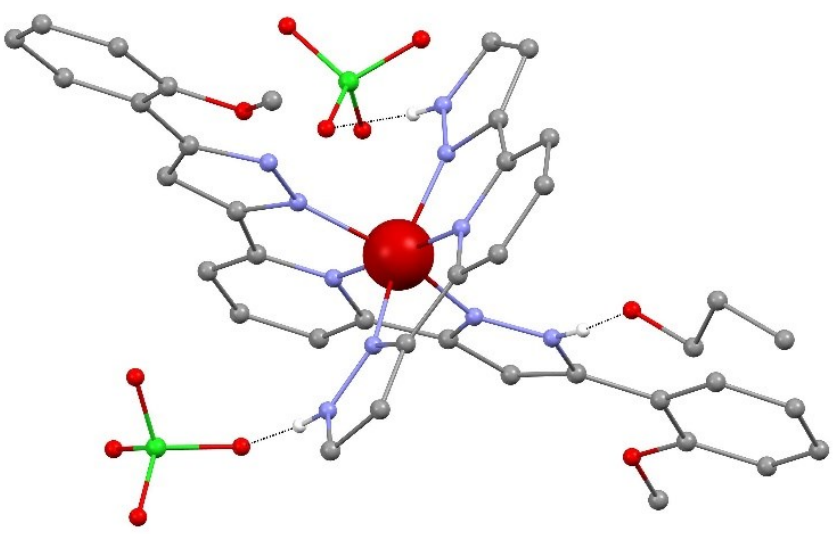

Figure 4. Representation of the asymmetric unit of 3.PrOH. Large red ball, Fe; red, O; grey, C; blue, N; green, $\mathrm{Cl}$; white, $\mathrm{H}$. Only hydrogen atoms bound to nitrogen atoms are shown. Hydrogen bridges are shown as dashed lines.

Contrary to all the cases analysed before, here the solvent molecule is forming a $\mathrm{H}$-bond with the $\mathrm{H}_{2} \mathrm{~L}$ ligand (and not bpp), whereas both $\mathrm{ClO}_{4}{ }^{-}$ions interact with the $\mathrm{N}-\mathrm{H}$ groups of bpp. This indicates that the 2.Ac $\rightarrow$ 3. $\mathrm{PrOH}$ process is accompanied by significant structural rearrangements (see below). At $100 \mathrm{~K}$, the average of the $\mathrm{Fe}-\mathrm{N}$ bond lengths (1.951(9) $\AA$ ) indicates again that the metal centres are in the LS state, thus confirming that the transformation involves also a spin switching phenomenon. In contrast with the cases of 3.MeOH and 2. EtOH, exposure of 2.Ac to a humid $\mathrm{PrOH}$ atmosphere leads neither to incorporation of water nor of any additional, loosely bound molecule of alcohol. The resulting lattice exhibits an array of intermolecular interactions very similar to these described above (Fig. S9, Table S5). However, a close inspection of the mutual orientations of the complexes within these sheets reveals very striking differences; the orientation of two of the four first neighbours of each complex is inverted compared with the initial lattice (Fig. 5 and S9). The easiest way to achieve this 
arrangement is that each linear array of complexes within the sheets shifts one position with respect to the complexes of the adjacent array, in a direction approximately perpendicular to the orientation of ligands $\mathrm{H}_{2} \mathrm{~L}$ (Fig. 5). Such movements arising from SCSC transformations are rare but not unprecedented. ${ }^{26,}$ $28,62,74,75$ This rearrangement may be facilitated by concerted rotations of the methoxyphenyl rings at the ends of each $\mathrm{H}_{2} \mathrm{~L}$ donor. These rotations were detected during the solid-state process $\mathbf{1} \cdot \mathrm{Ac} \rightarrow \mathbf{2} \cdot \mathrm{Ac}^{46,72}$ and have been observed again during the thermal desorption of propanol molecules from 3.PrOH (see below).

It is hard to rationalize the reasons for the LS-to-HS spin switching upon absorption of alcohols by $\mathbf{2}$.Ac. The formation of $\mathrm{O} \cdots \mathrm{H}-\mathrm{N}$ hydrogen bonds could explain it, however, the SCO accompanying the 1.Ac $\rightarrow$ 2.Ac transformation occurs without incidence on any hydrogen bonding. Therefore, other structural reasons are playing a role and they are hard to disentangle from the rest.

The sheets of complexes of the resulting structure are now separated by $9.920 \AA$. The decrease of inter-sheet separation with respect to $\mathbf{3} \cdot \mathrm{MeOH}$ and $\mathbf{3} \cdot \mathrm{EtOH}$ is noticeable, considering that propanol is the largest alcohol of the three. This underscores the impact that the partially occupied $\mathrm{H}_{2} \mathrm{O}$ and $\mathrm{MeOH}$ (or EtOH) molecules in between these planes has in separating the planes. A higher separation is also observed for 1.Ac, which features disordered acetone molecules intercalated in between the layers.
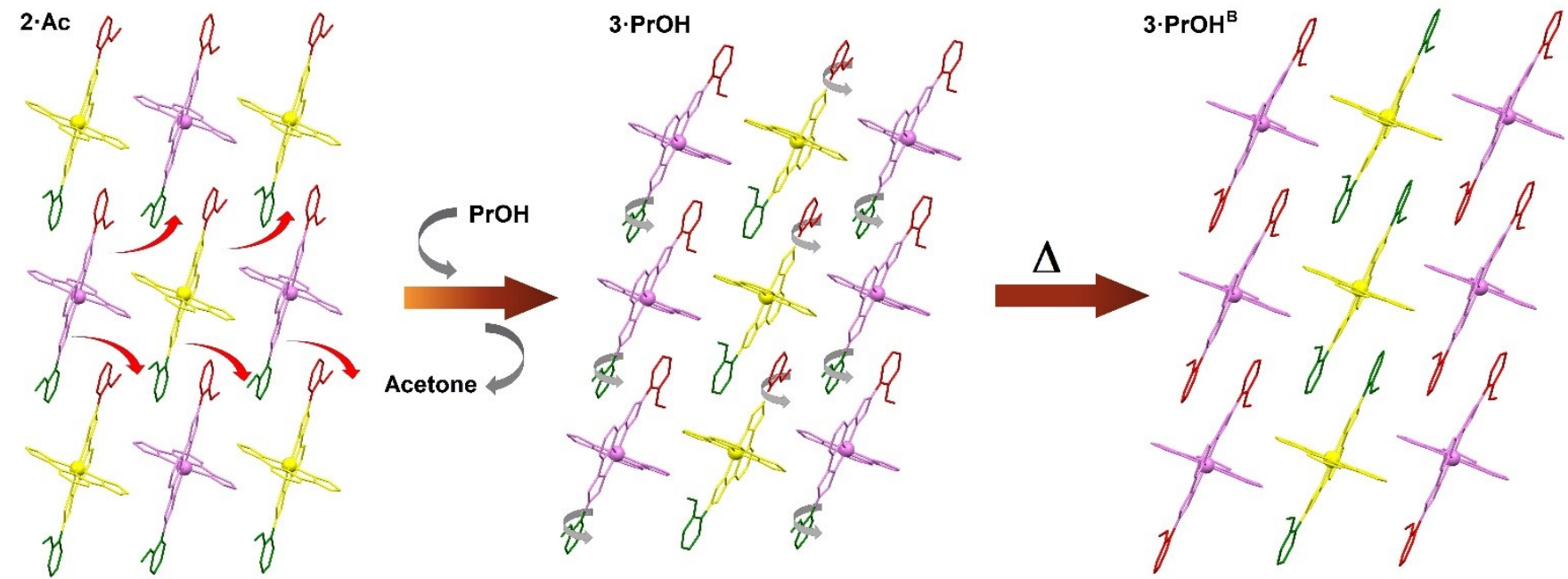

Figure 5. (left) Solid-state transformation 2.Ac $\rightarrow$ 3.PrOH, emphasising the rearrangement of the complexes $\left[\mathrm{Fe}(\mathrm{bpp})\left(\mathrm{H}_{2} \mathrm{~L}\right)\right]^{2+}$. Yellow and violet colours represent the two possible orientations of the complexes as a function of the $\mathrm{H}_{2} \mathrm{~L}$ and bpp positions with respect to the plane containing the cations. Green and red denote the orientation of the methoxy groups of $\mathrm{H}_{2} \mathrm{~L}$ with respect to this plane (upwards and downwards, respectively). Red arrows show the mutual displacement of the chains within the sheets, necessary to undergo the rearrangement; (right) Representation of the 3. $\mathrm{PrOH}^{\mathrm{A}} \rightarrow \mathbf{3} \cdot \mathrm{PrOH}^{\mathrm{B}}$ solid-state transformation (see text for details) indicating with grey arrows the $\approx 180^{\circ}$ rotations occurring on $50 \%$ of distal methoxyphenyl rings of the $\mathrm{H}_{2} \mathrm{~L}$ ligands.

\section{Ability of [ Fe(bpp) $\left.\left(\mathrm{H}_{2} \mathrm{~L}\right)\right]\left(\mathrm{ClO}_{4}\right)_{2} \cdot \mathrm{C}_{3} \mathrm{H}_{6} \mathrm{O}(2 \cdot \mathrm{Ac})$ to detect alcohols

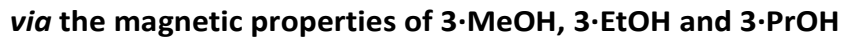

In all cases, the incorporation of $\mathrm{MeOH}, \mathrm{EtOH}$, or $\mathrm{PrOH}$ into the lattice of $\mathbf{2} \cdot \mathrm{Ac}$ is readily detected visually within a large interval of temperatures, including ambient, because the originally orange/yellow crystals turn dark red as a result of the HS to LS state switching. It is of interest to know if the detection through the magnetic response can be made specific for each alcohol. The magnetic properties of $\mathbf{3} \cdot \mathrm{MeOH}, \mathbf{3} \cdot \mathrm{EtOH}$ and $\mathbf{3} \cdot \mathrm{PrOH}$ were thus investigated in the 5-375 $\mathrm{K}$ temperature range under a constant magnetic field of $5 \mathrm{kG}$. At $250 \mathrm{~K}$, the product $\chi_{M} T$ (where $\chi_{M}$ is the molar paramagnetic susceptibility) amounts to $0.06 / 0.13 / 0.18 \mathrm{~cm}^{3} \mathrm{Kmol}^{-1}$ (in the $3 \cdot \mathrm{MeOH} / 3 \cdot \mathrm{EtOH} / 3 \cdot \mathrm{PrOH}$ format; Fig. S10) consistent with the LS state indicated by the dark red colour and the crystallographic parameters in the three cases (see above). These $\chi_{M} T$ values remain approximately constant upon heating up to room temperature. However, they start to increase when raising the temperature further, with values at $375 \mathrm{~K}$ of $2.25 / 3.48 / 1.06 \mathrm{~cm}^{3} \mathrm{Kmol}^{-1}$, unveiling distinct spin conversion processes occurring at three different temperatures (approx. 350/315/>375 K, Fig. 6). Remarkably, for $3 . \mathrm{MeOH} \chi_{M} T$ reaches a maximum of $2.47 \mathrm{~cm}^{3} \mathrm{Kmol}^{-1}$ at $368 \mathrm{~K}$, before decreasing again to its final value. If the temperature is maintained constant at $375 \mathrm{~K}$ for $40 \mathrm{~min}$., $\chi_{M} T$ decreases slightly for $3 \cdot \mathrm{MeOH}$ and for $3 \cdot \mathrm{EtOH}$ (to 1.98 and $3.35 \mathrm{~cm}^{3} \mathrm{Kmol}^{-1}$, respectively, see Fig. S10) while it increases for $3 \cdot \mathrm{PrOH}$ (to 2.11 $\left.\mathrm{cm}^{3} \mathrm{Kmol}^{-1}\right)$. Therefore, the thermal treatment unveils spin conversion processes that must be coupled to other phenomena, such as solvent desorption. Only in the case of 3.EtOH the thermal response is in appearance a conventional SCO process. However, the possibility of concomitant solvent loss processes also exists for this compound. The behaviour of 3. $\mathrm{MeOH}$ and 3.PrOH must be interpreted in these terms, with the formation of intermediate states with specific magnetic properties. The occurrence of an intermediate phase with distinct magnetic properties was for example already detected during the process of solvate desorption 1.Ac $\rightarrow \mathbf{2} \cdot \mathrm{Ac}$, where 0.5 equivalents of acetone are released. ${ }^{72}$ Thermogravimetric analyses (TGA) of compounds 3.MeOH, 3.EtOH and 3.PrOH indeed reveal that the three compounds experience a weight 
loss upon heating (see SI for details, Fig S11), from temperatures that correlate reasonably well with the beginning of the respective increases of $\chi_{M} T$ (Fig. 6). This confirms that the spin conversion phenomena first observed upon heating are concomitant with the depletion of solvate molecules and can thus be the combined result of a thermal SCO of the solvated species and a transformation to a fully or partially de-solvated material, with different magnetic properties, as previously observed on related materials. ${ }^{18,50}$ Particularly characteristic is the case of $\mathbf{3} \cdot \mathrm{MeOH}$, for which the two processes can probably be deconvoluted. Indeed, TGA indicate that both $3 \cdot \mathrm{MeOH}$ and 3.PrOH transform into fully de-solvated materials, termed here 4." $\mathrm{MeOH}^{\prime \prime}$ and 4." $\mathrm{PrOH}^{\prime \prime}$, respectively. The initial increase of $\chi_{M} T$ for $3 \cdot \mathrm{MeOH}$ likely corresponds to its thermal SCO, while the decrease at temperatures above $365 \mathrm{~K}$ would be due to the transformation into the fully de-solvated material 4." $\mathrm{MeOH}^{\prime \prime}$ Both 4." $\mathrm{MeOH}^{\prime \prime}$ and 4."PrOH" exhibit virtually the same magnetic properties (Fig. S10); a gradual thermal SCO with a characteristic temperature close to $375 \mathrm{~K}$. This latter behaviour can thus be attributed to that of the solvent free species $\left[\mathrm{Fe}(\mathrm{bpp})\left(\mathrm{H}_{2} \mathrm{~L}\right)\right]\left(\mathrm{ClO}_{4}\right)_{2}$ for which the single crystal structure was determined (see below). The case of "3.EtOH" remains less clear since the composition of the de-solvated material 4."EtOH" cannot be determined with confidence. Indeed, according to TGA, it retains a certain amount of lattice solvent, difficult to determine, while the compound exhibits magnetic properties that could be interpreted as resulting from the system in more than one state (Fig. S10).

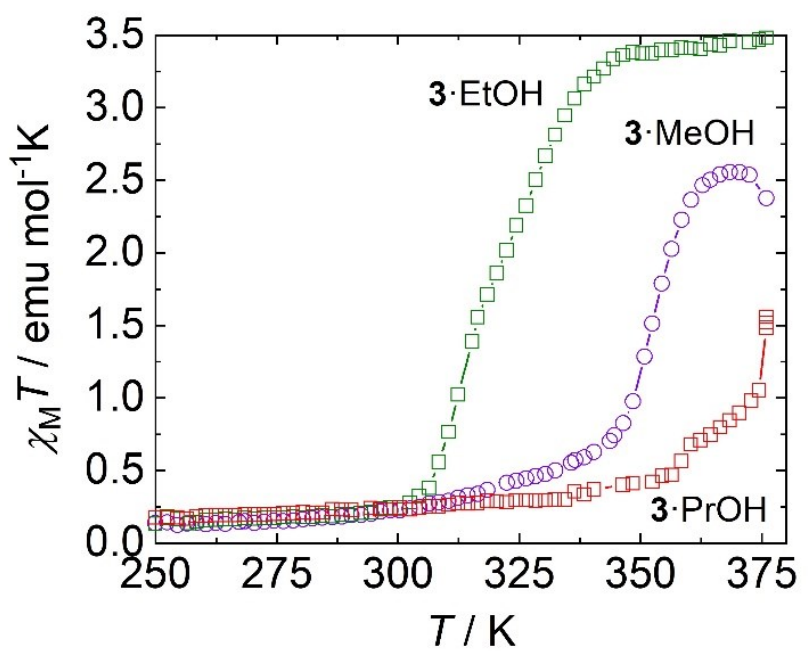

Figure 6. Plots of $\chi_{M} T$ vs $T$ for microcrystalline samples of $\mathbf{3} \cdot \mathrm{MeOH}$ (purple), $\mathbf{3} \cdot \mathrm{EtOH}$ (green) and 3.PrOH (red) when heating from 250 to $375 \mathrm{~K}$.

The above experiments confirm that the detection of $\mathrm{MeOH}$, $\mathrm{EtOH}$ or PrOH can be made, selectively, via the analysis of the magnetic properties of the crystals obtained after exposure to alcohols, by inspection of the temperature at which the LS to HS switching of the resulting crystals occurs (Fig. 6).

$\begin{array}{lll}\text { Snapshots of PrOH desorption } & \text { from } \\ {\left[\mathrm{Fe}(\mathrm{bpp})\left(\mathrm{H}_{2} \mathrm{~L}\right)\right]\left(\mathrm{ClO}_{4}\right)_{2} \cdot \mathrm{PrOH}(3 \cdot \mathrm{PrOH})} & \text { by SCXRD } & \end{array}$

The structure of 3.PrOH was determined at $100 \mathrm{~K}$ on a good quality single crystal (see experimental). This crystal, termed specifically $3 \cdot \mathrm{PrOH}^{\mathrm{A}}$, was maintained on the goniometer while the temperature was increased at a rate of $6 \mathrm{~K} / \mathrm{min}$ up to $375 \mathrm{~K}$ twice and to $400 \mathrm{~K}$, where it was maintained for 3, 30 and 15 min. respectively. After each temperature plateau, the crystal was cooled rapidly $(20 \mathrm{~K} / \mathrm{min}$ ) to $100 \mathrm{~K}$ and its SCXRD diffraction data then collected (furnishing the structures of $3 \cdot \mathrm{PrOH}^{\mathrm{B}}$, 3. $\mathrm{PrOH}^{\mathrm{C}}$ and 4." $\mathrm{PrOH}^{\prime \prime}$, respectively).

Structure of $\mathbf{3} \cdot \mathrm{PrOH}^{\mathrm{B}}$. The asymmetric unit of $\mathbf{3} \cdot \mathrm{PrOH}^{\mathrm{B}}$, $\left[\mathrm{Fe}(\mathrm{bpp})\left(\mathrm{H}_{2} \mathrm{~L}\right)\right]\left(\mathrm{ClO}_{4}\right)_{2} \cdot 0.88 \mathrm{PrOH}$, reflects the fact that ca. $12 \%$ of the $\mathrm{PrOH}$ molecules have left the structure after this thermal treatment. All the non-active components form $\mathrm{H}$-bonds with the same $\mathrm{N}-\mathrm{H}$ groups of the complex as originally (Fig. 7). One of the $\mathrm{ClO}_{4}{ }^{-}$anions is now disordered over two positions (in the 0.81:0.19 occupancy ratio). The Fe-N bond distances (avg. = 1.956(12) A) reveal that the Fe centres are still in the LS state. The most important observation, however, is that, in contrast with the crystal before the thermal treatment, the ligand $\mathrm{H}_{2} \mathrm{~L}$ of the complex in 3. $\mathrm{PrOH}^{\mathrm{B}}$ is now in the syn, syn conformation (Fig. 7). This means that the first thermal treatment of $3 \cdot \mathrm{PrOH}$ causes a rotation of $50 \%$ of the methoxyphenyl rings of the structure (Fig. 5) while the lattice propanol molecule is still almost fully occupied. This rotation does not change the mutual positions of the complexes, which exhibit the usual arrangement, as in 3.PrOH.

Structure of 3.PrOHC. This structure reveals the release of propanol molecules, now with only $35 \%$ occupancy $\left(\left[\mathrm{Fe}(\mathrm{bpp})\left(\mathrm{H}_{2} \mathrm{~L}\right)\right]\left(\mathrm{ClO}_{4}\right)_{2} \cdot 0.5 \mathrm{PrOH}\right.$, Fig. 7). The PrOH fragment is now disordered over two positions (0.25:0.10 occupation), while one of the $\mathrm{ClO}_{4}{ }^{-}$anions is now further disordered over its two positions (0.46:0.54). In addition, the methoxyphenyl moiety adjacent to the disordered $\mathrm{PrOH}$ now also shows some disorder over two positions that are slightly shifted and rotated (0.63:0.35 occupation), and related to the presence/absence of the partial $\mathrm{PrOH}$ molecule. The outer carbons of the pyridine ring of the bpp ligand also show some lateral disorder, obvious in their displacement ellipsoids. All this can be taken as a snapshot of the process of PrOH extrusion. The bond distances around the $\mathrm{Fe}(\mathrm{II})$ ions (average 1.95(4) Å) confirm that the LS state is conserved. The arrangement of the complexes within the lattice is now maintained (Fig S12), with no additional rotations of methoxyphenyl rings detected. Thus, this new thermal treatment releases over $50 \%$ of the $\mathrm{PrOH}$ molecules with no significant changes to the lattice, besides the local disorders showing the rearrangements allowing the diffusion of the PrOH molecules through the crystal.

Structure of 4."PrOH". The crystal after the last thermal treatment is devoid of propanol, with formula $\left[\mathrm{Fe}(\mathrm{bpp})\left(\mathrm{H}_{2} \mathrm{~L}\right)\right]\left(\mathrm{ClO}_{4}\right)_{2}$ (Fig. 7), while the $\mathrm{Fe}(\mathrm{II})$ ion maintains the LS state at $100 \mathrm{~K}$ (avg. Fe-N bond distances, 1.95(3) Å). From its color at room temperature (also dark red), the system appears also LS at room temperature, consistent with the magnetic data. The lattice also remains the same (Fig. S13). The transition 3. $\mathrm{PrOH}^{\mathrm{C}} \rightarrow$ 4." $\mathrm{PrOH}^{\prime \prime}$ thus represents exclusively the release of the PrOH molecules still present inside the crystal network. 
Mechanism of PrOH desorption. The SCXRD structural determinations of 3.PrOH ${ }^{X}(X=A, B, C)$ and 4." $\mathrm{PrOH}^{\prime \prime}$ provide a unique picture of the events occurring during the process of desorption of the lattice propanol molecules from 3.PrOH. This solid-state transformation involves significant structural rearrangements in addition to a change in chemical composition and magnetic properties, while preserving crystallographic order as well as the integrity of the single crystals. Contrary to what had been observed for the acetone desorption process 1.Ac $\rightarrow \mathbf{2} \cdot A c$ previously reported, ${ }^{72}$ no coexistence of two or more crystallographic phases occurs at any point of the process. Thus, the sequential structural study suggests that the migration of molecules of propanol, takes place by diffusion through the lattice in a continuous manner. The crystal network does not exhibit channels allowing the free circulation of molecules. The lattice must thus provide for a suitable mechanism for their diffusion towards the exterior. Inspection of the structure reveals a pathway (Fig. S14) parallel to the crystallographic $a$ direction that the molecules of propanol can use to escape the lattice without altering significantly the network of intermolecular interactions that ensure the crystal's integrity. Consistent with this, the $\mathrm{ClO}_{4}{ }^{-}$ anions located near this pathway suffer disorder, as determined crystallographically after the migration starts (3. $\mathrm{PrOH}^{\mathrm{B}}, \mathbf{3} \cdot \mathrm{PrOH}^{\mathrm{C}}$ and 4."PrOH"). The motion of PrOH species through this pathway must take place with the help of concerted rotations of the methoxyphenyl groups. The syn,anti to syn,syn conformation mutation of the ligand $\mathrm{H}_{2} \mathrm{~L}$ observed after the 3. $\mathrm{PrOH}^{\mathrm{A}} \rightarrow \mathbf{3} \cdot \mathrm{PrOH}^{\mathrm{B}}$ step is a clear indication that the migration is occurring in this way. These rotations were also detected in this complex, concomitant to the $\mathbf{1} \cdot \mathrm{Ac} \rightarrow \mathbf{2} \cdot$ Ac process, $^{72}$ and also in the related complex $\left[\mathrm{Fe}(\mathrm{bbp})\left(\mathrm{H}_{2} \mathrm{~L}\right)\right]\left(\mathrm{ClO}_{4}\right)_{2}(\mathrm{bbp}=2,6$-bis(benzimidazol-2-yl)-pyridine), following a crystallographic phase transition coupled to a SCO. ${ }^{50}$ The fact that the processes leading to structures 3. $\mathrm{PrOH}^{\mathrm{C}}$ and $4 . " \mathrm{PrOH}^{\prime \prime}$ do not reveal any further conformation changes of $\mathrm{H}_{2} \mathrm{~L}$ does not exclude that such rotations occur during the course of these thermal treatments and of the PrOH migration accompanying them. The same may be speculated about the three solvent exchange transformations 2. $\mathrm{Ac} \rightarrow \mathbf{3} \cdot \mathrm{ROH}(\mathrm{R}=\mathrm{Me}, \mathrm{Et}, \mathrm{Pr})$ described above, as well as the two other processes of guest extrusion, $3 \cdot \mathrm{MeOH}$ $\rightarrow$ 4." $\mathrm{MeOH}^{\prime \prime}$ and 3.EtOH $\rightarrow$ 4."EtOH". Similar conformation changes as a result of migration of species within molecular lattices have been observed on other SCSC transformations requiring thorough SCSC studies. ${ }^{76}$

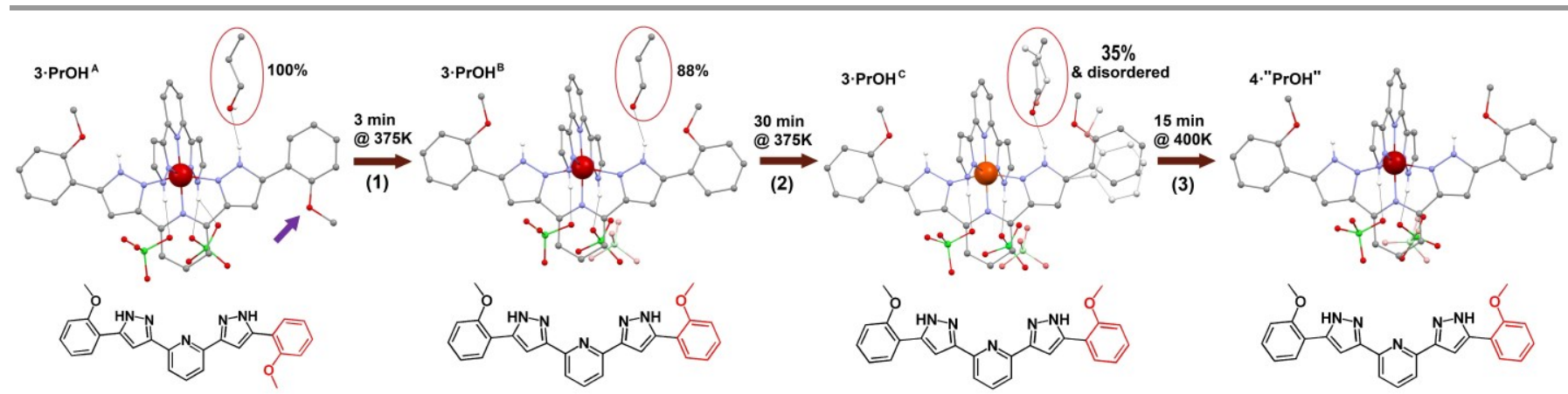

Figure 7. (top) Representation of the asymmetric unit of 3. $\mathrm{PrOH}^{\mathrm{X}}(\mathrm{X}=\mathrm{A}, \mathrm{B} \mathrm{C}$ or $\mathrm{D})$ and $4 \cdot{ }^{\prime \prime} \mathrm{PrOH}^{\prime \prime}$, as determined after the sequence of solid-state changes 3.PrOH $\rightarrow$ 3.PrOH ${ }^{\mathrm{B}}$ (1), $3 \cdot \mathrm{PrOH}^{\mathrm{B}} \rightarrow 3 \cdot \mathrm{PrOH}^{\mathrm{C}}(2)$ and $3 \cdot \mathrm{PrOH}^{\mathrm{C}} \rightarrow 4 \cdot{ }^{\prime \prime} \mathrm{PrOH}^{\prime \prime}$ (3) corresponding to the process of release of the ${ }^{n} \mathrm{PrOH}$ molecules from the lattice. The gradual rearrangement of the complex $\left[\mathrm{Fe}(\mathrm{bpp})\left(\mathrm{H}_{2} \mathrm{~L}\right)\right]^{2+}$ and the rest of the unit cell components is emphasised. The occupancy of the PrOH molecule at each stage is shown and the disorder of PrOH, the distal methoxyphenyl and $\mathrm{ClO}_{4}^{-}$is shown as a fully coloured and a faded component in each case. A violet arrow shows the methoxyphenyl group that rotates $180^{\circ}$ during the first treatment (1). (bottom) Conformation of the $\mathrm{H}_{2} \mathrm{~L}$ ligand at each of the stages studied, emphasising in red colour the methoxyphenyl ring that rotates in the process.

\section{Experimental}

\section{Synthesis.}

The ligand bpp was synthesised following a procedure described in the literature. The ligand 2,6-bis(5-(2-methoxyphenyl)pyrazol-3-yl)pyridine $\left(\mathrm{H}_{2} \mathrm{~L}\right)$ was synthesised as previously described by our group, as were the complexes $\left[\mathrm{Fe}(\mathrm{bpp})\left(\mathrm{H}_{2} \mathrm{~L}\right)\right]\left(\mathrm{ClO}_{4}\right)_{2} \cdot 1.5 \mathrm{C}_{3} \mathrm{H}_{6} \mathrm{O} \quad$ (1. Ac) and $\left[\mathrm{Fe}(\mathrm{bpp})\left(\mathrm{H}_{2} \mathrm{~L}\right)\right]\left(\mathrm{ClO}_{4}\right)_{2} \cdot 1.25 \mathrm{MeOH} \cdot 0.5 \mathrm{H}_{2} \mathrm{O} \quad(3 \cdot \mathrm{MeOH})$. Single crystals of complex 1.Ac were heated in air to $393 \mathrm{~K}$ for 2 hours to generate the complex $\left[\mathrm{Fe}(\mathrm{bpp})\left(\mathrm{H}_{2} \mathrm{~L}\right)\right]\left(\mathrm{ClO}_{4}\right)_{2} \cdot \mathrm{C}_{3} \mathrm{H}_{6} \mathrm{O}$ (2.Ac), prior to solvent exchange experiments. Caution: Perchlorate salts of metal complexes are potentially explosive. Only small quantities of material should be prepared, and the samples should be handled with care.
$\left[\mathrm{Fe}(\mathrm{bpp})\left(\mathrm{H}_{2} \mathrm{~L}\right)\right]\left(\mathrm{ClO}_{4}\right)_{2} \cdot \mathbf{1 . 5}$ EtOH$\cdot \mathbf{0 . 5} \mathrm{H}_{2} \mathrm{O}(3 \cdot \mathrm{EtOH})$. Single crystals of 3.EtOH were obtained by exposing single crystals of compound

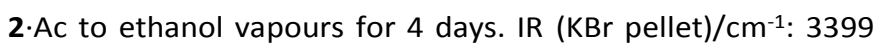
(w), $2942(w), 1616(w), 1473(\mathrm{~m}), 1259(w), 1121(\mathrm{~s}), 1109$ (s), $1099(\mathrm{~s}), 1075(\mathrm{~s}), 1015(\mathrm{~m}), 773(\mathrm{~m}), 622(\mathrm{~m})$. Elemental analysis calcd (\%) for $\mathrm{C}_{36} \mathrm{H}_{30} \mathrm{Cl}_{2} \mathrm{FeN}_{10} \mathrm{O}_{10} \cdot \mathrm{C}_{2} \mathrm{H}_{5} \mathrm{OH} \cdot \mathrm{H}_{2} \mathrm{O}: \mathrm{C} 47.87, \mathrm{H} 4.02, \mathrm{~N}$ 14.69; found (\%): C 47.66, H 3.99, N 15.05.

$\left[\mathrm{Fe}(\mathrm{bpp})\left(\mathrm{H}_{2} \mathrm{~L}\right)\right]\left(\mathrm{ClO}_{4}\right)_{2} \cdot \operatorname{PrOH}$ (3.PrOH). Single crystals of 3.PrOH were obtained by exposing single crystals of compound $\mathbf{2}$.Ac to 1-propanol vapours for 4 days. IR ( $\mathrm{KBr}$ pellet)/ $\mathrm{cm}^{-1}: 3405(\mathrm{~m})$, $2939(w), 1617(w), 1585(\mathrm{~m}), 1450(\mathrm{~m}), 1258(\mathrm{~m})$, 1124(s), 1090(s), 1050(m), 1017(m), 770(m), $626(\mathrm{~m})$. elemental analysis calcd (\%) for $\mathrm{C}_{36} \mathrm{H}_{30} \mathrm{Cl}_{2} \mathrm{FeN}_{10} \mathrm{O}_{10} \cdot \mathrm{C}_{3} \mathrm{H}_{7} \mathrm{OH}$ : C 49.33, $\mathrm{H} 4.03, \mathrm{~N}$ 14.75; found (\%): C 48.87, H 3.91, N 15.05. The molecular structure obtained by SCXRD from these crystals was unfortunately of poor quality. We thus report only a 
characteristic unit cell (Table S1) while refraining from describing it in detail. It is however, as its unit cell indicates, exactly the same as that obtained on good quality single crystals, synthesized with the alternative procedure described below.

Good quality single crystals of 3.PrOH were obtained by exposure of single crystals of $\left[\mathrm{Fe}(\mathrm{bpp})\left(\mathrm{H}_{2} \mathrm{~L}\right)\right]\left(\mathrm{ClO}_{4}\right)_{2} \cdot 1.5 \mathrm{C}_{3} \mathrm{H}_{6} \mathrm{O}$ (1.Ac) to vapours of PrOH inside a closed vessel at $50{ }^{\circ} \mathrm{C}$ during 16 hours. This produced a mixture of red and yellow crystals. The SCXRD molecular structure of the red crystals corresponds exactly to 3.PrOH, of much better quality than these obtained from 2.Ac. Attempts to obtain a pure homogeneous phase using this methodology by exploring different experimental conditions failed. Nevertheless, the crystals of 3.PrOH obtained in this manner furnished excellent structural data for this compound and could be used to investigate the process of thermal depletion of PrOH from the lattice.

\section{Physical Measurements.}

Variable-temperature magnetic susceptibility data for al compounds were obtained with a Quantum Design MPMS-XL SQUID magnetometer at the "Unitat de Mesures Magnètiques" of the Universitat de Barcelona and Pascal's constants were used to estimate diamagnetic corrections to the molar paramagnetic susceptibility, and a correction was applied for the sample holder. IR spectra were recorded on $\mathrm{KBr}$ pellets, in the range $4000-400 \mathrm{~cm}^{-1}$, with a Thermo Nicolet Avatar $330 \mathrm{FT}$ IR spectrometer. Elemental analyses were performed with a Perkin-Elmer Series II CHNS/O Analyser 2400 at the Servei de Microanàlisi of the CSIC, Barcelona. TGA experiments were performed using a Mettler-Toledo TGA-851e thermos-balance. Samples were introduced in alumina crucibles of $70 \mathrm{~mL}$ volume and heated at ca. $2.3 \mathrm{~K} / \mathrm{min}$ from room temperature to $393 \mathrm{~K}$ under a dry nitrogen atmosphere.

\section{Single Crystal X-ray Diffraction (SCXRD).}

Data for compounds 3.EtOH, 3. $\mathrm{PrOH}^{\mathrm{X}}(\mathrm{X}=\mathrm{A}, \mathrm{B}, \mathrm{C})$ and 4." $\mathrm{PrOH}^{\prime \prime}$ were obtained, at $250 \mathrm{~K}$ for the first and $100 \mathrm{~K}$ otherwise, on a Bruker APEX II CCD diffractometer at the Advanced Light Source beam-line 11.3.1 at Lawrence Berkeley National Laboratory, from a silicon 111 monochromator $(\lambda=0.77490 \AA)$. The data for 3. $\mathrm{PrOH}^{\mathrm{B}}$, 3. $\mathrm{PrOH}^{\mathrm{C}}$ and 4." $\mathrm{PrOH}^{\prime \prime}$ were obtained on the same crystal used for $\mathbf{3} \cdot \mathrm{PrOH}^{\mathrm{A}}$ and after annealing at $375 \mathrm{~K}$ for $3 \mathrm{~min}$ and $30 \mathrm{~min}$ or to $400 \mathrm{~K}$ for $10 \mathrm{~K}$, respectively, and cooling rapidly to $100 \mathrm{~K}$ after each annealing. Data reduction and absorption corrections were performed with SAINT and SADABS, respectively. ${ }^{77}$ All structures were solved by intrinsic phasing with SHELXT ${ }^{78}$ and refined on $\mathrm{F}^{2}$ with SHELXL. ${ }^{79}$ All details can be found in CCDC 1996673-1996677 (3. EtOH, 3. $\cdot \mathrm{PrOH}^{\mathrm{X}}$ (X=A,B,C) and 4." $\mathrm{PrOH}^{\prime \prime}$ ) that contain the supplementary crystallographic data for this paper. These data can be obtained free of charge from The Cambridge Crystallographic Data Center via https://www.ccdc.cam.ac.uk/structures/. Crystallographic and refinement parameters are summarized in Table S1. Selected hydrogen bonding and intermolecular contacts details are given in Tables S2, S4 and S5.

\section{Conclusions}

The acetone molecules of crystallisation contained within the molecular material $\left[\mathrm{Fe}(\mathrm{bpp})\left(\mathrm{H}_{2} \mathrm{~L}\right)\right]\left(\mathrm{ClO}_{4}\right)_{2} \cdot \mathrm{C}_{3} \mathrm{H}_{6} \mathrm{O}$ (2.Ac) are replaced at room temperature, in the solid-state, by small alcohol molecules (sometimes with incorporation of water) from their saturated vapours, entering the lattice in amounts per mole of $1.25 \mathrm{MeOH} \cdot 0.5 \mathrm{H}_{2} \mathrm{O}, 1.5 \mathrm{EtOH} \cdot 0.5 \mathrm{H}_{2} \mathrm{O}$ and ${ }^{n} \mathrm{PrOH}$, respectively. However, iso-propanol is not capable of entering the lattice. These transformations occur in a SCSC manner, allowing the detailed structural characterisation of the resulting compounds by SCXRD. The nature of the alcohol absorbed can be detected by the signature of the thermal magnetic behaviour of the resulting material. In all cases, a HS-to-LS spin switching occurs with this solvent exchange, and the products obtained become HS again on increasing the temperature as a result of the combination of SCO and solvent extrusion processes, in each case with a different characteristic temperature. The process of thermal desorption of propanol $\left[\mathrm{Fe}(\mathrm{bpp})\left(\mathrm{H}_{2} \mathrm{~L}\right)\right]\left(\mathrm{ClO}_{4}\right)_{2} \cdot \mathrm{PrOH} \rightarrow\left[\mathrm{Fe}(\mathrm{bpp})\left(\mathrm{H}_{2} \mathrm{~L}\right)\right]\left(\mathrm{ClO}_{4}\right)_{2}+\mathrm{PrOH} \uparrow$ (3.PrOH $\rightarrow$ 4." $\mathrm{PrOH}^{\prime \prime}$ ) from a single crystal can be stopped and quenched at low temperature $(100 \mathrm{~K})$ at various intermediate stages. This allows the mechanism of this solid-state process to be studied by SCXRD, furnishing unique information. The data suggest a pathway for the escape of $\mathrm{PrOH}$ molecules by diffusion through the lattice with the help of the concerted rotation by approximately $180^{\circ}$ of one of the two unique methoxyphenyl rings of $\mathrm{H}_{2} \mathrm{~L}$ (with consequent conformation changes). The detailed understanding of solid-state processes of molecular lattices acting as small molecule detectors will help in the molecular design of such important class of micro or nano devices.

\section{Conflicts of interest}

There are no conflicts to declare.

\section{Acknowledgements}

This research was supported by Spanish MINECO (CTQ200906959, CTQ2015-68370-P, PGC2018-098630-B-I00, MAT201786826-R, CTQ2015-64486-R), the Aragón government (E31_17R) and EU quantERA (SUMO, PCI2018-093106, PCI2018093116), G. A. thanks the Generalitat de Catalunya for the prize ICREA Academia 2018. The Advanced Light Source is supported by the Director, Office of Science, Office of Basic Energy Sciences of the U. S. Department of Energy under contract no. DE-AC02-05CH11231.

\section{Notes and references}

1. M. Ding, R. W. Flaig, H.-L. Jiang and O. M. Yaghi, Carbon capture and conversion using metal-organic frameworks and MOF-based materials, Chem. Soc. Rev., 2019, 48, 27832828.

2. J. Lee, O. K. Farha, J. Roberts, K. A. Scheidt, S. T. Nguyen and J. T. Hupp, Metal-organic framework materials as catalysts, Chem. Soc. Rev., 2009, 38, 1450-1459. 
3. Q. Wang and D. Astruc, State of the Art and Prospects in Metal-Organic Framework (MOF)-Based and MOF-Derived Nanocatalysis, Chem. Rev., 2020, 120, 1438-1511.

4. E. Fernandez-Bartolome, J. Santos, A. Gamonal, S. Khodabakhshi, L. J. McCormick, S. J. Teat, E. C. Sanudo, J. S. Costa and N. Martin, A Three-Dimensional Dynamic Supramolecular "Sticky Fingers" Organic Framework, Angew. Chem., Int. Ed., 2019, 58, 2310-2315.

5. M.-J. Tsai, C.-Y. Li and J.-Y. Wu, Luminescent Zn(ii) coordination polymers as efficient fluorescent sensors for highly sensitive detection of explosive nitroaromatics, CrystEngComm, 2018, 20, 6762-6774.

6. X. Zheng, R. Fan, K. Xing, K. Zhu, P. Wang and Y. Yang, Smart cationic coordination polymer: A single-crystal-to-singlecrystal approach for simultaneous detection and removal of perchlorate in aqueous media, Chem. Eng. J. (Lausanne), 2020, 380, 122580.

7. H. Furukawa, K. E. Cordova, M. O'Keeffe and O. M. Yaghi, The Chemistry and Applications of Metal-Organic Frameworks, Science, 2013, 341, 974-+.

8. N. Stock and S. Biswas, Synthesis of Metal-Organic Frameworks (MOFs): Routes to Various MOF Topologies, Morphologies, and Composites, Chem. Rev., 2012, 112, 933969.

9. S. Horike, S. Shimomura and S. Kitagawa, Soft porous crystals, Nature Chem., 2009, 1, 695-704.

10. A. Chaudhary, A. Mohammad and S. M. Mobin, Recent Advances in Single-Crystal-to-Single-Crystal Transformation at the Discrete Molecular Level, Cryst. Growth Des., 2017 17, 2893-2910.

11. R. M. Payne and C. L. Oliver, Single-crystal-to-single-crysta transformation of the desolvation of a cyclotriveratryleneacetonitrile inclusion complex via a gating mechanism with subsequent polymorphism, CrystEngComm, 2016, 18, 79657971.

12. J. V. Knichal, W. J. Gee, A. D. Burrows, P. R. Raithby, S. J. Teat and C. C. Wilson, A facile single crystal to single crystal transition with significant structural contraction on desolvation, Chem. Commun., 2014, 50, 14436-14439.

13. S. M. Mobin, A. K. Srivastava, P. Mathur and G. K. Lahiri, Vapor-Diffusion-Mediated Single Crystal-to-Single Crysta Transformation of a Discrete Dimeric Copper(II) Complex to a Discrete Tetrameric Copper(II) Complex, Inorg. Chem., 2009, 48, 4652-4654

14. V. I. Nikolayenko, D. C. Castell, D. P. van Heerden and L. J. Barbour, Guest-Induced Structural Transformations in a Porous Halogen-Bonded Framework, Angew. Chem., Int Ed., 2018, 57, 12086-12091.

15. M. Kato, H. Ito, M. Hasegawa and K. Ishii, Soft Crystals: Flexible Response Systems with High Structural Order, Chem., Eur. J., 2019, 25, 5105-5112.

16. R. Hilfiker and M. von Raumer, Polymorphism in the Pharmaceutical Industry: Solid Form and Drug Development, Wiley, 2019.

17. M. F. Pina, M. Zhao, J. F. Pinto, J. J. Sousa, C. S. Frampton, V. Diaz, O. Suleiman, L. Fábián and D. Q. M. Craig, An Investigation into the Dehydration Behavior of Paroxetine $\mathrm{HCl}$ Form I Using a Combination of Thermal and Diffraction Methods: The Identification and Characterization of a New Anhydrous Form, Cryst. Growth Des., 2014, 14, 3774-3782.

18. C. Bartual-Murgui, C. Codina, O. Roubeau and G. Aromí, A Sequential Method to Prepare Polymorphs and Solvatomorphs of $\mathrm{Fe}(1,3-\mathrm{bpp})(2) \quad(\mathrm{ClO} 4)(2)$ center dot $\mathrm{nH}(2) \mathrm{O}(\mathrm{n}=0,1,2)$ with Varying Spin-Crossover Behaviour, Chem., Eur. J., 2016, 22, 12767-12776.

19. S. Bhandary and D. Chopra, Observation of Rapid Desolvation of Hexafluorobenzene Involving Single-Crystal-
to-Single-Crystal Phase Transition in a Nonporous Organic Host, Cryst. Growth Des., 2018, 18, 27-31.

20. B. Fours, Y. Cartigny, S. Petit and G. Coquerel, Formation of new polymorphs without any nucleation step. Desolvation of the rimonabant monohydrate: directional crystallisation concomitant to smooth dehydration, Faraday Discuss., 2015, 179, 475-488.

21. M. A. Little, S. Y. Chong, M. Schmidtmann, T. Hasell and A. I. Cooper, Guest control of structure in porous organic cages, Chem. Commun., 2014, 50, 9465-9468.

22. Y. Guo, S. Xue, M. M. Dîrtu and Y. Garcia, A versatile iron(ii)based colorimetric sensor for the vapor-phase detection of alcohols and toxic gases, J. Mater. Chem., C, 2018, 6, 38953900.

23. R. G. Miller and S. Brooker, Reversible quantitative guest sensing via spin crossover of an iron(II) triazole, Chem. Sci., 2016, 7, 2501-2505.

24. Y. Shigeta, A. Kobayashi, T. Ohba, M. Yoshida, T. Matsumoto, H. C. Chang and M. Kato, Shape-Memory Platinum(II) Complexes: Intelligent Vapor-History Sensor with ON-OFF Switching Function, Chem., Eur. J., 2016, 22 2682-2690.

25. M. du Plessis, V. I. Nikolayenko and L. J. Barbour, SingleCrystal to Single-Crystal Uptake of Volatile Solids and Associated Chromatic Response in a Porous Metallocycle, Inorg. Chem., 2018, 57, 12331-12337.

26. H. Yamagishi, H. Sato, A. Hori, Y. Sato, R. Matsuda, K. Kato and T. Aida, Self-assembly of lattices with high structural complexity from a geometrically simple molecule, Science, 2018, 361, 1242-1245.

27. T. Ogoshi, Y. Hamada, R. Sueto, Y. Sakata, S. Akine, A. M. P. Moeljadi, H. Hirao, T. Kakuta, T. Yamagishi and M. Mizuno, Host-Guest Complexation Using Pillar 5 arene Crystals: Crystal-Structure Dependent Uptake, Release, and Molecular Dynamics of an Alkane Guest, Chem., Eur. J., 2019, 25, 2497-2502.

28. Z. Wang, N. Sikdar, S.-Q. Wang, X. Li, M. Yu, X.-H. Bu, Z. Chang, X. Zou, Y. Chen, P. Cheng, K. Yu, M. J. Zaworotko and Z. Zhang, Soft Porous Crystal Based upon Organic Cages That Exhibit Guest-Induced Breathing and Selective Gas Separation, J. Am. Chem. Soc., 2019, 141, 9408-9414.

29. M. Jin, T. Sumitani, H. Sato, T. Seki and H. Ito, MechanicalStimulation-Triggered and Solvent-Vapor-Induced Reverse Single-Crystal-to-Single-Crystal Phase Transitions with Alterations of the Luminescence Color, J. Am. Chem. Soc., 2018, 140, 2875-2879.

30. J. Miguel-Donet, J. López-Cabrelles, N. Calvo Galve, E. Coronado and G. Mínguez Espallargas, Two Consecutive Magneto-Structural Gas-Solid Transformations in NonPorous Molecular Materials, Chem., Eur. J., 2018, 24, 1242612432.

31. X.-W. Wu, F. Pan, S. Yin, J.-Y. Ge, G.-X. Jin, P. Wang and J.-P. $\mathrm{Ma}$, Solvent-induced structural transformation and magnetic modulation in 1D copper(ii) polymers based on a semi-rigid ligand containing 4-amino-1,2,4-triazole, CrystEngComm, 2018, 20, 3955-3959.

32. D. Shao, L. Shi, F.-X. Shen, X.-Q. Wei, O. Sato and X.-Y. Wang, Reversible On-Off Switching of the Hysteretic Spin Crossover in a Cobalt(II) Complex via Crystal to Crystal Transformation, Inorg. Chem., 2019, 58, 11589-11598.

33. D. Shao, L. Shi, L. Yin, B. L. Wang, Z. X. Wang, Y. Q. Zhang and $X$. Y. Wang, Reversible on-off switching of both spin crossover and single-molecule magnet behaviours via a crystal-to-crystal transformation, Chem. Sci., 2018, 9, 79867991

34. M. A. Halcrow, Spin-Crossover Materials: Properties and Applications, Wiley, West Sussex, UK, 2013. 
35. A. Bousseksou, G. Molnar, L. Salmon and W. Nicolazzi, Molecular spin crossover phenomenon: recent achievements and prospects, Chem. Soc. Rev., 2011, 40, 3313-3335.

36. P. Gutlich and H. A. Goodwin, in Spin Crossover in Transition Metal Compounds I, eds. P. Gutlich and H. A. Goodwin, 2004, vol. 233, pp. 1-47.

37. J. A. Real, A. B. Gaspar and M. C. Munoz, Thermal, pressure and light switchable spin-crossover materials, Dalton Trans. 2005, 2062-2079.

38. P. Gamez, J. S. Costa, M. Quesada and G. Aromí, Iron SpinCrossover compounds: from fundamental studies to practical applications, Dalton Trans., 2009, 7845-7853.

39. P. Gutlich, A. Hauser and H. Spiering, Thermal and optical switching of iron(II) complexes, Angew. Chem., Int. Ed., 1994, 33, 2024-2054.

40. P. Gütlich, Y. Garcia and H. A. Goodwin, Spin crossover phenomena in $\mathrm{Fe}($ ) complexes, Chem. Soc. Rev., 2000, 29, 419-427.

41. J. A. Real, A. B. Gaspar, V. Niel and M. C. Munoz, Communication between iron(II) building blocks in cooperative spin transition phenomena, Coord. Chem. Rev., 2003, 236, 121-141.

42. M. A. Halcrow, Structure:function relationships in molecular spin-crossover complexes, Chem. Soc. Rev., 2011, 40, 41194142.

43. S. Rodríguez-Jiménez, H. L. C. Feltham and S. Brooker, NonPorous Iron(II)-Based Sensor: Crystallographic Insights into a Cycle of Colorful Guest-Induced Topotactic Transformations, Angew. Chem., Int. Ed., 2016, 55, 1506715071.

44. F.-L. Yang, X. Chen, W.-H. Wu, J.-H. Zhang, X.-M. Zhao, Y.-H. Shi and $F$. Shen, Spin switching in tris(8aminoquinoline)iron(ii)(BPh4)2: quantitative guest-losing dependent spin crossover properties and single-crystal-tosingle-crystal transformation, Dalton Trans., 2019, 48, 231 241.

45. S. Rodríguez-Jiménez and S. Brooker, Qualitative Guest Sensing via Iron(II) Triazole Complexes, Inorg. Chem., 2019, 58, 8188-8197.

46. J. S. Costa, S. Rodriguez-Jimenez, G. A. Craig, B. Barth, C. M. Beavers, S. J. Teat and G. Aromi, Three-Way Crystal-toCrystal Reversible Transformation and Controlled Spin Switching by a Nonporous Molecular Material, J. Am. Chem. Soc., 2014, 136, 3869-3874.

47. B. Li, R. J. Wei, J. Tao, R. B. Huang, L. S. Zheng and Z. P. Zheng, Solvent-Induced Transformation of Single Crystals of a SpinCrossover (SCO) Compound to Single Crystals with Two Distinct SCO Centers, J. Am. Chem. Soc., 2010, 132, 15581566.

48. R. J. Wei, J. Tao, R. B. Huang and L. S. Zheng, Reversible and Irreversible Vapor-Induced Guest Molecule Exchange in Spin-Crossover Compounds, Inorg. Chem., 2011, 50, 85538564.

49. J. E. Clements, P. R. Airey, F. Ragon, V. Shang, C. J. Kepert and S. M. Neville, Guest-Adaptable Spin Crossover Properties in a Dinuclear Species Underpinned by Supramolecular Interactions, Inorg. Chem., 2018, 57, 1493014938.

50. C. Bartual-Murgui, R. Diego, S. Vela, S. J. Teat, O. Roubeau and G. Aromí, A Spin-Crossover Molecular Material Describing Four Distinct Thermal Pathways, Inorg. Chem., 2018, 57, 11019-11026.

51. W.-B. Chen, Y.-C. Chen, M. Yang, M.-L. Tong and W. Dong, Water molecule induced reversible single-crystal-to-singlecrystal transformation between two trinuclear $\mathrm{Fe}(\mathrm{ii})$ complexes with different spin crossover behaviour, Dalton Trans., 2018, 47, 4307-4314.
52. W.-B. Chen, J.-D. Leng, Z.-Z. Wang, Y.-C. Chen, Y. Miao, M. L. Tong and W. Dong, Reversible crystal-to-crystal transformation from a trinuclear cluster to a 1D chain and the corresponding spin crossover ( $\mathrm{SCO}$ ) behaviour change, Chem. Commun., 2017, 53, 7820-7823.

53. W. Huang, F. Shen, M. Zhang, D. Wu, F. Pan and O. Sato, Room-temperature switching of magnetic hysteresis by reversible single-crystal-to-single-crystal solvent exchange in imidazole-inspired Fe(ii) complexes, Dalton Trans., 2016, 45, 14911-14918.

54. C. Zheng, J. Xu, F. Wang, J. Tao and D. Li, Spin crossover and reversible single-crystal to single-crystal transformation behaviour in two cyanide-bridged mixed-valence \{FellI2Fell2\} clusters, Dalton Trans., 2016, 45, 17254-17263.

55. Y.-Y. Zhu, C.-W. Liu, J. Yin, Z.-S. Meng, Q. Yang, J. Wang, T Liu and S. Gao, Structural phase transition in a multi-induced mononuclear Fell spin-crossover complex, Dalton Trans., 2015, 44, 20906-20912.

56. Y.-H. Luo, L.-J. Yang, Q.-L. Liu, Y. Ling, W. Wang and B.-W. Sun, Lattice water molecules tuned spin-crossover for an iron(ii) complex with thermal hysteresis, Dalton Trans., 2014, 43, 16937-16942.

57. Y.-T. Wang, S.-T. Li, S.-Q. Wu, A.-L. Cui, D.-Z. Shen and H.-Z. Kou, Spin Transitions in Fe(II) Metallogrids Modulated by Substituents, Counteranions, and Solvents, J. Am. Chem. Soc., 2013, 135, 5942-5945.

58. R.-J. Wei, J. Tao, R.-B. Huang and L.-S. Zheng, Reversible and Irreversible Vapor-Induced Guest Molecule Exchange in Spin-Crossover Compounds, Inorg. Chem., 2011, 50, 85538564.

59. R.-J. Wei, Q. Huo, J. Tao, R.-B. Huang and L.-S. Zheng, SpinCrossover Fell4 Squares: Two-Step Complete Spin Transition and Reversible Single-Crystal-to-Single-Crystal Transformation, Angew. Chem., Int. Ed., 2011, 50, 89408943.

60. M. Darawsheh, L. A. Barrios, O. Roubeau, S. J. Teat and G. Aromí, Guest-, Light- and Thermally-Modulated Spin Crossover in Fe-2(II) Supramolecular Helicates, Chem., Eur. J., 2016, 22, 8635-8645.

61. W.-T. Deng, Z.-B. Shen, L.-J. Su, Y.-H. Hua, Z.-X. Chen and J. Tao, Ring-Opening Polymeric Single-Crystal-to-SingleCrystal Transformation in a Co(II) Compound, Cryst. Growth Des., 2018, 18, 587-591.

62. J. L. Atwood, L. J. Barbour, A. Jerga and B. L. Schottel, Guest Transport in a Nonporous Organic Solid via Dynamic van der Waals Cooperativity, Science, 2002, 298, 1000-1002.

63. A. Worthy, A. Grosjean, M. C. Pfrunder, Y. A. Xu, C. Yan, G. Edwards, J. K. Clegg and J. C. McMurtrie, Atomic resolution of structural changes in elastic crystals of copper(II) acetylacetonate, Nature Chem., 2018, 10, 65-69.

64. M. A. Halcrow, Iron(II) complexes of 2,6-di(pyrazol-1yl)pyridines-A versatile system for spin-crossover research, Coord. Chem. Rev., 2009, 253, 2493-2514.

65. L. J. Kershaw Cook, R. Mohammed, G. Sherborne, T. D. Roberts, S. Alvarez and M. A. Halcrow, Spin state behavior of iron(II)/dipyrazolylpyridine complexes. New insights from crystallographic and solution measurements, Coord. Chem. Rev., 2015, 289-290, 2-12.

66. G. A. Craig, O. Roubeau and G. Aromi, Spin state switching in 2,6-bis(pyrazol-3-yl)pyridine (3-bpp) based $\mathrm{Fe}(\mathrm{II})$ complexes, Coord. Chem. Rev., 2014, 269, 13-31.

67. M. L. Scudder, D. C. Craig and H. A. Goodwin, Hydrogen bonding influences on the properties of heavily hydrated chloride salts of iron(ii) and ruthenium(ii) complexes of 2,6bis(pyrazol-3-yl)pyridine, 2,6-bis(1,2,4-triazol-3-yl)pyridine and 2,2':6',2"-terpyridine, CrystEngComm, 2005, 7, 642 649. 
68. R. Pritchard, C. A. Kilner and M. A. Halcrow, Iron(II) complexes with a terpyridine embrace packing motif show remarkably consistent cooperative spin-transitions, Chem. Commun., 2007, 577-579.

69. L. A. Barrios, E. Peyrecave-Lleixa, G. A. Craig, O. Roubeau, S. J. Teat and G. Aromí, Unusual Crystal Packing in a Family of Fe $\{2,6$-bis(pyrazol-3-yl)pyridine $\}(2) \quad(2+)$ Compounds and the Effect on the Occurrence of Spin Crossover and Its Cooperative Character, Eur. J. Inorg. Chem., 2014, 60136021.

70. L. A. Barrios, C. Bartual-Murgui, E. Peyrecave-Lleixa, B. Le Guennic, S. J. Teat, O. Roubeau and G. Aromí, Homoleptic versus Heteroleptic Formation of Mononuclear $\mathrm{Fe}(\mathrm{II})$ Complexes with Tris-Imine Ligands, Inorg. Chem., 2016, 55, 4110-4116.

71. L. J. K. Cook, R. Kulmaczewski, O. Cespedes and M. A. Halcrow, Different Spin-State Behaviors in Isostructural Solvates of a Molecular Iron(II) Complex, Chem., Eur. J., 2016, 22, 1789-1799.

72. G. Aromí, C. M. Beavers, J. S. Costa, G. A. Craig, G. MínguezEspallargas, A. Orera and O. Roubeau, Snapshots of a solidstate transformation: coexistence of three phases trapped in one crystal, Chem. Sci., 2016, 7, 2907-2915.

73. X. Sheng, E. Li, Y. Zhou, R. Zhao, W. Zhu and F. Huang, Separation of 2-Chloropyridine/3-Chloropyridine by Nonporous Adaptive Crystals of Pillararenes with Different Substituents and Cavity Sizes, J. Am. Chem. Soc., 2020.

74. C. Ge, J. Liu, X. Ye, Q. Han, L. Zhang, S. Cui, Q. Guo, G. Liu, Y. Liu and $X$. Tao, Visualization of Single-Crystal-to-SingleCrystal Phase Transition of Luminescent Molecular Polymorphs, The Journal of Physical Chemistry C, 2018, 122, 15744-15752.

75. J. T. A. Jones, D. Holden, T. Mitra, T. Hasell, D. J. Adams, K. E. Jelfs, A. Trewin, D. J. Willock, G. M. Day, J. Bacsa, A. Steiner and A. I. Cooper, On-Off Porosity Switching in a Molecular Organic Solid, Angew. Chem., Int. Ed., 2011, 50, 749-753.

76. C. D. Assouma, A. Crochet, Y. Chérémond, B. Giese and K. M. Fromm, Kinetics of Ion Transport through Supramolecular Channels in Single Crystals, Angew. Chem., Int. Ed., 2013, 52, 4682-4685.

77. G. M. Sheldrick, 2012, SAINT and SADABS, Bruker AXS Inc., Madison, Wisconsin, USA.

78. G. Sheldrick, SHELXT - Integrated space-group and crystalstructure determination, Acta Cryst. A, 2015, 71, 3-8.

79. G. Sheldrick, Crystal structure refinement with SHELXL, Acta Cryst. C, 2015, 71, 3-8. 
This is a peer-reviewed, accepted author manuscript of the following article: Costa, J. S., Rodríguez-Jiménez, S., Craig, G. A., Barth, B., Beavers, C. M., Teat, S. J., Gagnon, K. J., Barrios, L. A., Roubeau, O., \& Aromí, G. (2020). Selective signalling of alcohols by a molecular lattice and mechanism of single-crystal-to-single-crystal transformations. Inorganic Chemistry Frontiers, 7(17), 3165-3175.

https://doi.org/10.1039/D0QI00645A

\section{ARTICLE}

\section{TOC Figure}

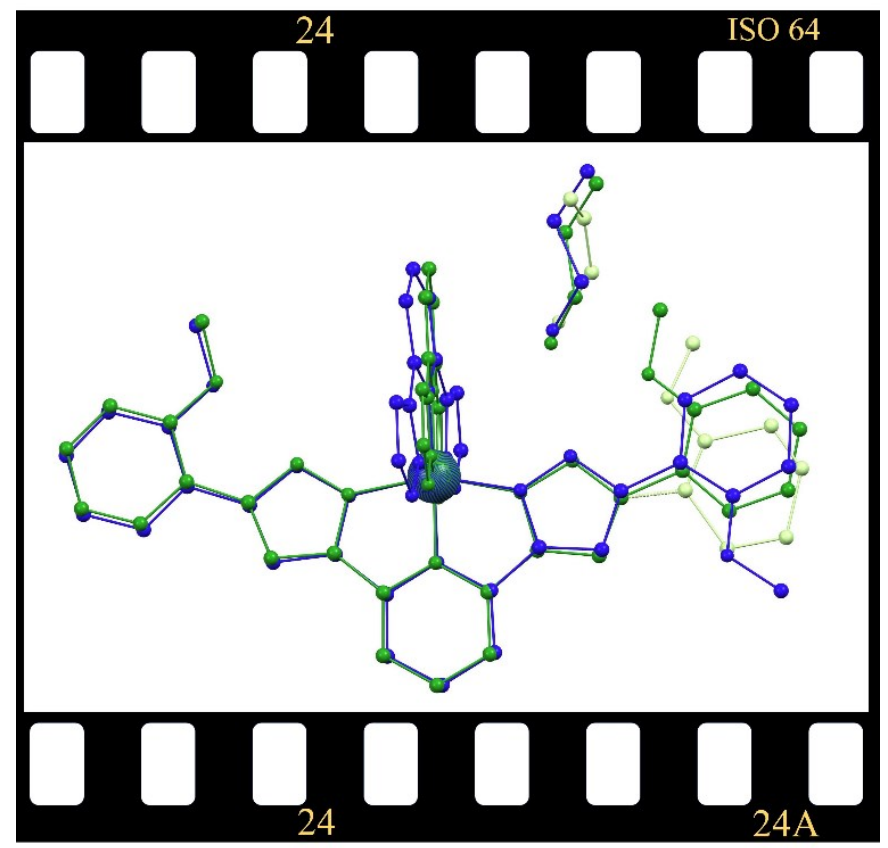

